Gut, 1980, 21, 1035-1040

\title{
Porcine intestinal adenomatosis: epithelial dysplasia and infiltration
}

\author{
L ROBERTS, * A C ROWLAND, $\dagger$ AND G H K LAWSON $†$ \\ From the Veterinary Investigation Centre, Mill of Craibstone, Bucksburn, Aberdeen, and the \\ Department of Veterinary Pathology, Edinburgh University, Veterinary Field Station, Roslin, Easter Bush, \\ Midlothian
}

SUMMARY Occasionally in cases of porcine intestinal adenomatosis (PIA) epithelial dysplasia is seen with infiltration of the epithelium into underlying tissues and spread, via the lymphatics, to drainage lymph nodes. The intracellular bacterium Campylobacter sputorum subspecies mucosalis, associated with PIA, can be demonstrated in the epithelial cells of the metasases. This dysplasia and infiltration appears to be related to surface damage and inflammation.

Porcine intestinal adenomatosis (PIA), a transient but often extensive adenomatous proliferation of the intestinal mucosa of the young pig has been widely recorded. ${ }^{1-4}$ The clinical manifestations are of anorexia and a failure to thrive for a period of six to eight weeks. Recovery associated with resolution of the lesions occurs in the majority of cases (in preparation $)^{5}$, but secondary necrotic or progressive inflammatory changes can occur. ${ }^{6}$

Ultrastructural studies have demonstrated the presence of bacteria free within the apical cytoplasm of the adenomatous epithelial cells ${ }^{7}$ and this organism Campylobacter sputorum subspp. mucosalis ${ }^{8}$ is consistently recovered from the affected mucosa in cases of PIA. Although this condition histologically resembles a neoplasm, its behaviour is that of an infectious disease ${ }^{4}$ and the experimental transmission of PIA has been reported. ${ }^{9}$

This report describes the extension of adenomatous epithelium into the submucosa of the intestine and to the mesenteric lymph node. The infiltrating growth is contrasted within the normal close lymphoepithelial relationship seen in the porcine intestine.

\section{Methods}

The pigs in this study conformed to the clinical, gross pathological, and bacteriological description of PIA ${ }^{4111}$ and were mostly obtained from local

Received for publication 8 July 1980 farms, although one was an experimental case of PIA. ${ }^{9}$

Necropsy procedure and tissue processing for histological examinations were carried out as previously described. ${ }^{10}$ Most sections were routinely stained with haematoxylin and eosin, and, in addition, selected sections were stained by Levaditi's method for spirochaetes, Young's modification of Warthin-Starry, ${ }^{12}$ Martius Scarlet Blue, Masson's trichrome, and Gordon and Sweet's for reticulin.

\section{Results}

The histological structure of the pig's intestine conforms to the normal mammalian pattern, with longer villi demonstrable in the duodenum and jejunum than in the ileum. The extension of epithelium into the lymphoid tissue of the submucosa is a regular feature, especially in the Peyer's patch areas of the ileum, bringing the epithelium into intimate contact with the lymphoid tissue (Fig. 1).

In PIA the most remarkable feature of the adenomatous epithelium is its immaturity, and the presence of curved bacteria free within the apical cytoplasm. A full description of the histopathological and ultrastructural features of PIA has already been given $^{410}$ and the pertinent features are illustrated in Fig. 2. Where adenomatous change is established over an area of Peyer's patch, the immature epithelium typical of the condition is present, within the lymphoid tissue (Fig. 3) and may be readily differentiated from the epithelial dysplasia and infiltration described below. 


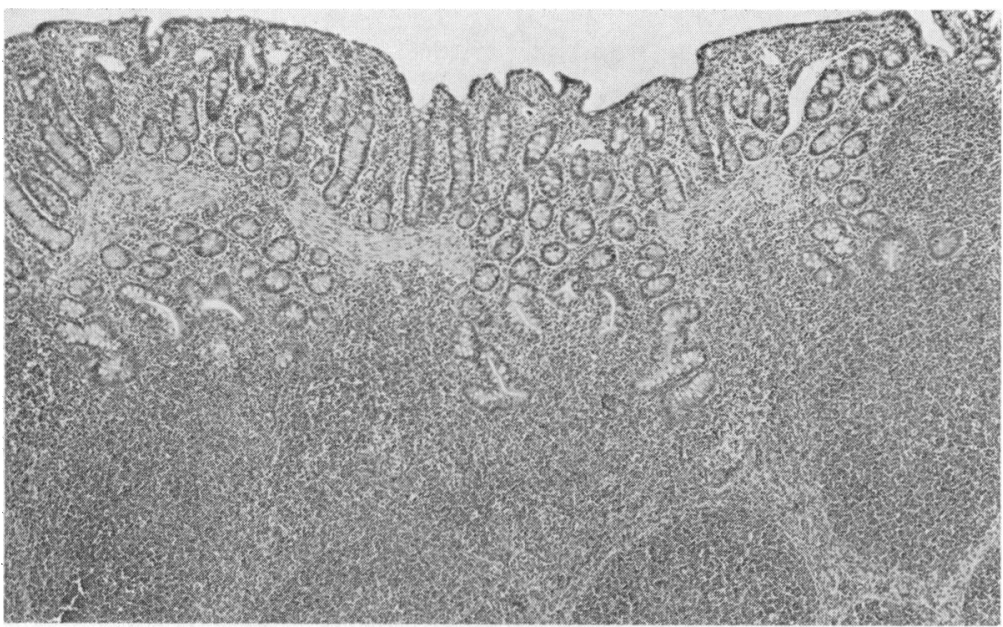

Fig. 1 Normal pig (terminal ileum) villi attenuated over Peyer's patches, and crypts extend deep into the underlying lymphoid tissue. Haematoxylin and eosin, $\times 60$.

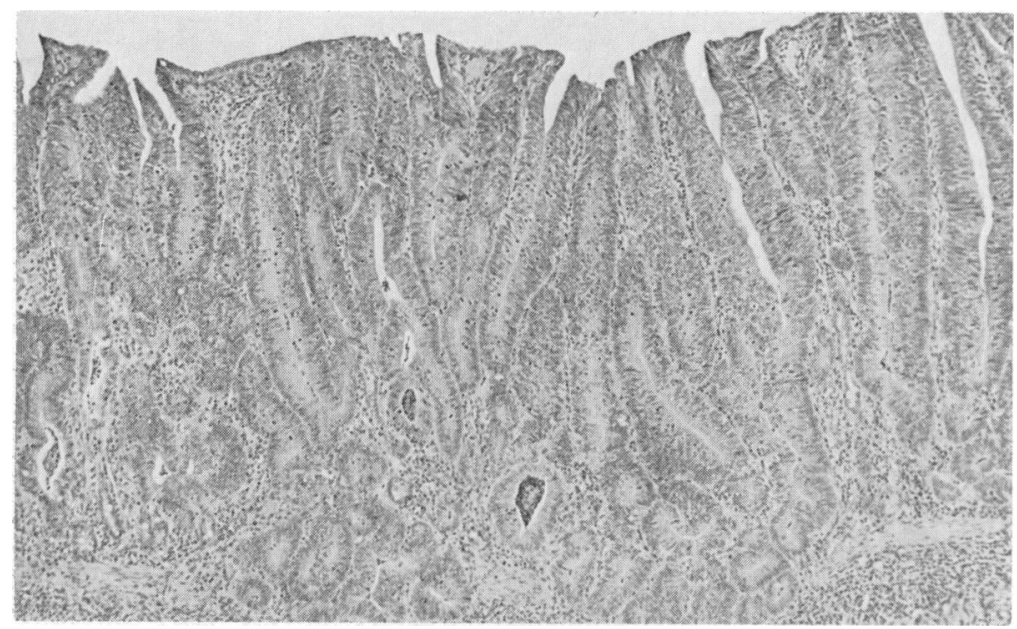

Fig. 2 Porcine intestinal adenomatosis (terminal ileum) adenomatous change involving the whole mucosa. The epithelium is immature, and there is an absence of goblet cells.

Haematoxylin and eosin, $\times 80$.

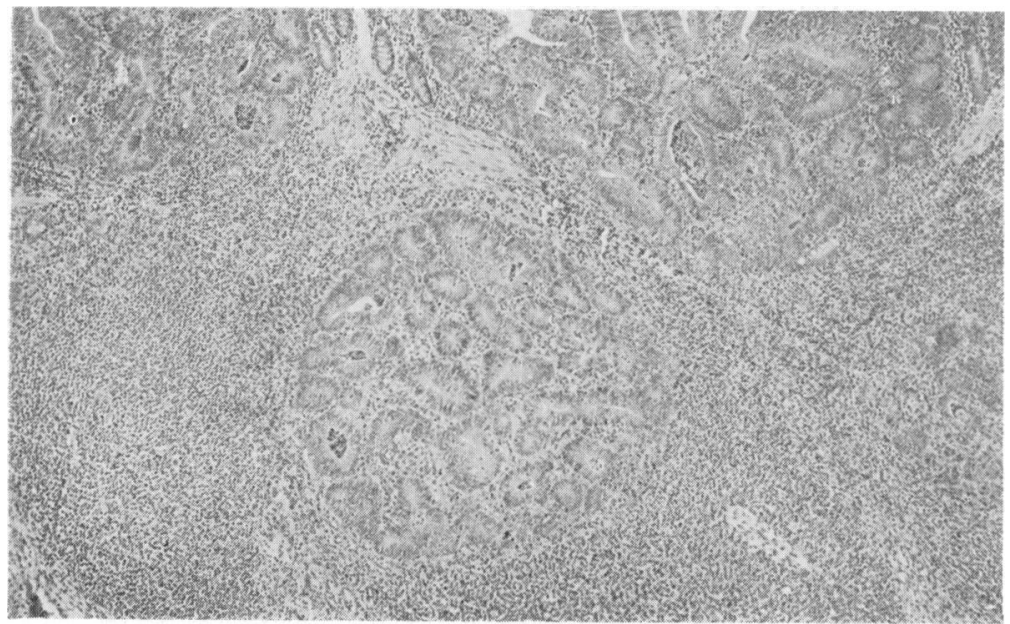

Fig. 3 Porcine intestinal adenomatosis (terminal ileum) a collection of adenomatous glands deep within a lymphoid nodule of Peyer's patches.

Haematoxylin and eosin, $\times 50$. 


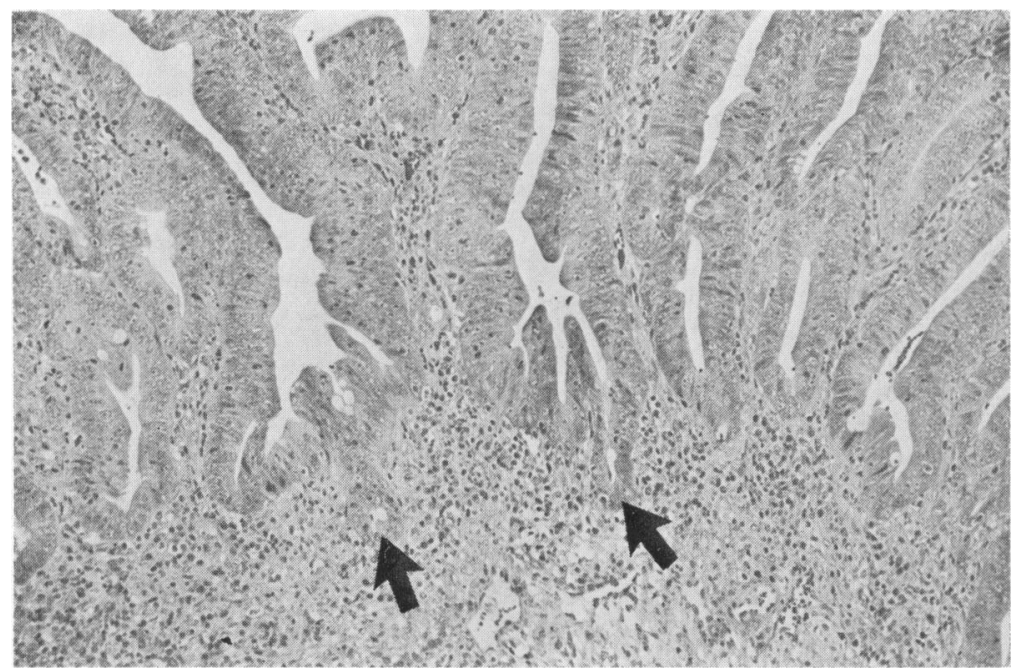

Fig. 4 Porcine intestinal adenomatosis (terminal ileum) the bases of the glands are irregular because of the protrusion of adenomatous epithelial cells (arrowed) into the surrounding lamina propria. Haematoxylin and eosin, $\times 120$.

Occasionally in cases of PIA a marked dysplasia* of the epithelium, especially of the deeper glands, with infiltration through the muscularis into the submucosa is observed. The infiltrative growth is seen most often, but not exclusively, in those cases in which there is damage to the surface epithelium, and an associated inflammatory response. Marked variation in the degree of infiltration is seen. In some cases the smooth outline of the glands is lost because of the irregular protrusions of cells into the surrounding lamina propria (Fig. 4), but the gland structure is retained. This change occurs in epithelium with a dysplastic appearance, and, although this dysplasia is more common at the base of glands, it is not confined to this site. A greater degree of infiltration is seen as cords or sheets of epithelial cells extending into the submucosa or underlying lymphoid tissue (Fig. 5). These epithelial cells vary from columnar to cuboidal, or even spindle-shaped, and only occasionally are glands formed by these infiltrating elements. The infiltrating growth can extend deep into the underlying tissue.

The reaction to these infiltrating tongues of epithelial cells is variable, with in some cases a marked connective tissue response (Fig. 5) and in others there is no apparent connective tissue proliferation, making it difficult to distinguish between infiltrating epithelial cells and the surrounding tissue (Fig. 6). Around many of the infiltrating epithelial cells there is no well-defined basement membrane.

*Dysplasia is used in preference to anaplasia, as it is considered that the change in PIA is essentially a failure of the epithelial cells to mature. Its transient nature, with complete resolution of the lesion, indicates that it is not truly a neoplastic condition and so it is considered inappropriate to refer to the change described here as anaplasia.

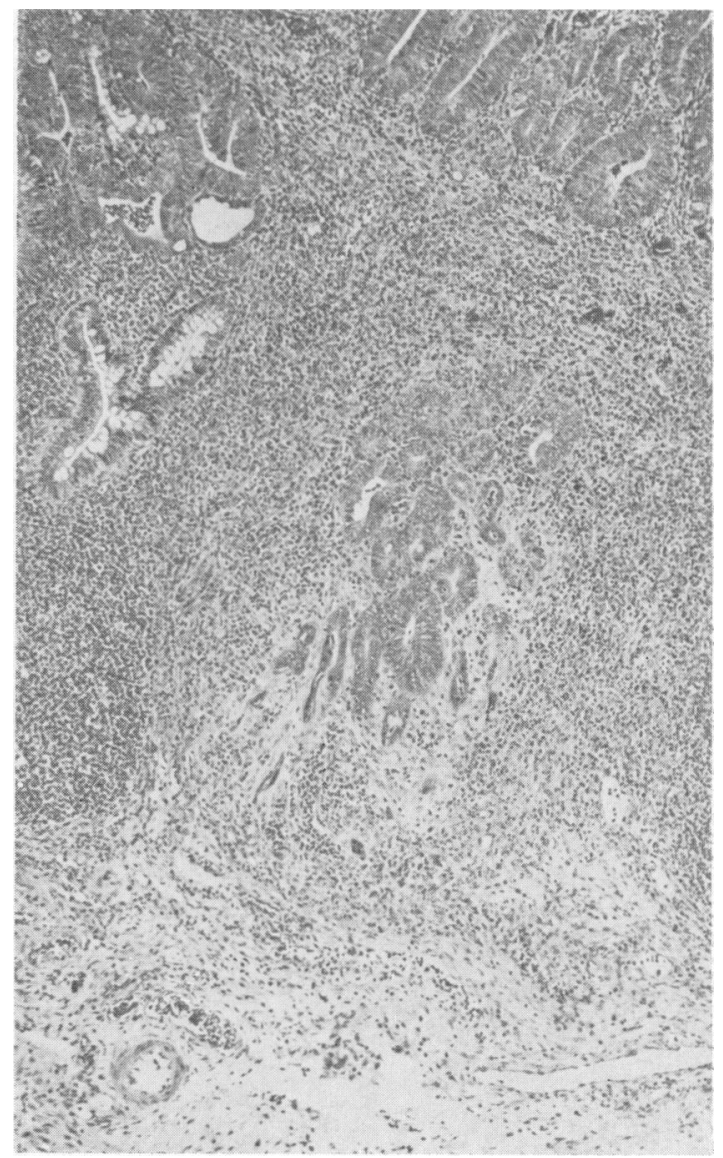

Fig. 5 Porcine intestinal adenomatosis (terminal ileum) cords of epithelial cells infiltrating into the underlying submucosa. Masson's trichrome, $\times 60$. 

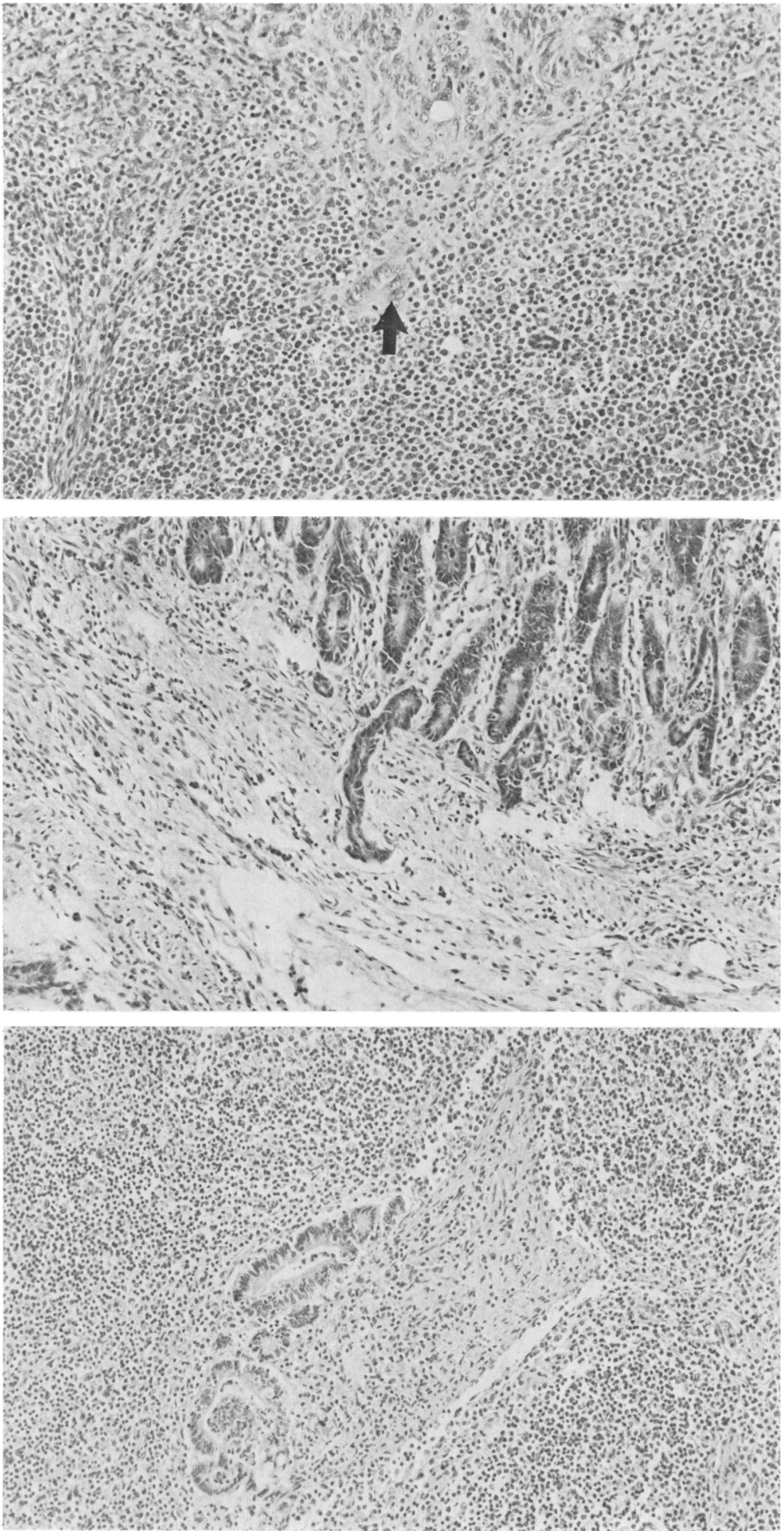

Fig. 6 Porcine intestinal adenomatosis (terminal ileum) infiltrating epithelial cells (arrowed) not surrounded by connective tissue. Haematoxylin and eosin, $\times 200$.

Fig. 7 Porcine intestinal adenomatosis (terminal ileum) a cord of infiltrating epithelial cells extending into an underlying lymphatic vessel. Haematoxylin and eosin, $\times 140$.

Fig. 8 Porcine intestinal adenomatosis (mesenteric lymph node) a collection of adenomatous glands in the lymph node draining a portion of affected ileum. Haematoxylin and eosin, $\times 120$. 


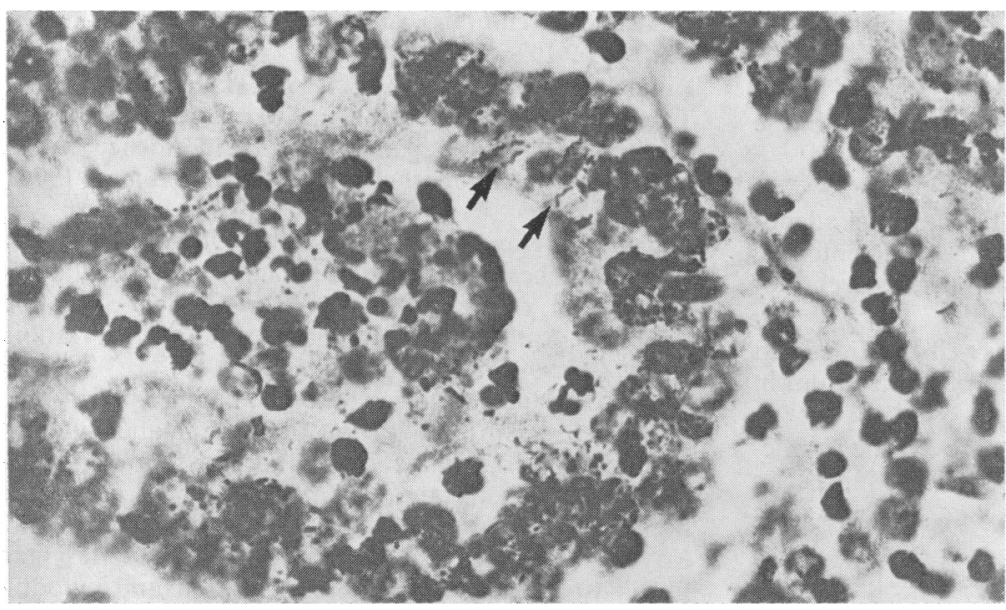

Fig. 9 Porcine intestinal adenomatosis (mesenteric lymph node) argyrophilic vibrio-shaped bacteria (arrowed) are present in the apical cytoplasm of adenomatous epithelial cells in a lymph node metastasis. Young's, $\times 850$.

Infiltrative growth brings epithelial cells close to lymphatic vessels, and infiltration into lymphatics is seen as tongues of epithelial cells protruding into the vessel (Fig. 7) or as clumps of cells within lymphatics. Spread to the outer layers of the gut wall has not been observed, but small foci of epithelial cells forming acini occur within the drainage mesenteric lymph nodes (Fig. 8.). No spread within or extension from these nodes has been recognised.

Argyrophilic curved bacteria are demonstrable in silver-stained sections, in the apical cytoplasm of the overlying adenomatous epithelium and in lower numbers in the infiltrating epithelial cells. They can also be shown in mestastases to the mesenteric lymph nodes (Fig. 9).

\section{Discussion}

That PIA is a transient disease is well established, ${ }^{45}$ unless secondary conditions develop. ${ }^{6}$ A detailed pathological study of this recovery has been made by Roberts et al. ${ }^{5}$ In fact, alimentary tract neoplasia in the pig, although reported, ${ }^{12 a}$ is very rare. ${ }^{13}$ It must be considered, therefore, that the lesions described in this report do not constitute a true neoplasm or a precancerous condition but a transient disorder of growth and maturation associated with the presence of mucosalis within the affected cells.

Why infiltration should occur in some of these cases is less easy to explain, but the consistent occurrence of surface inflammation associated with these lesions suggests the possibility that surface damage may depress the feedback mechanism responsible for inhibition of proliferation as reported by Rijke et al. ${ }^{14}$ This depression of the physiological control mechanism may result in a few cases in the disordered and vigorous growth of the deep epithel- ium with the results described. It must be emphasised however, that many cases of severe necrosis occur without the development of infiltrative lesions.

A close relationship exists between intestinal epithelial cells and the population of subjacent mesenchymal cells. ${ }^{1516}$ An alternative hypothesis to explain the infiltrative growth described here is some interference with this intimate epithelial-mesenchymal relationship after surface inflammatory change. These two cell populations show synchronous replication, migration, and differentiation; and in man immaturity of the pericryptal fibroblast sheath in adenomatous epithelium parallels the degree of immaturity of the overlying adenomatous epithelium. ${ }^{17}$

Herniation of the mucosal epithelium into the submucosa in chronic ulcerative colitis has been reported in man, ${ }^{18}$ and in non-human primates suffering from inflammatory disease of the colon, as well as in apparently normal animals. ${ }^{19}$ Epithelial dysplasia and carcinoma occur in chronic ulcerative colitis in man. ${ }^{20}$ In this latter condition, as in PIA cases showing dysplasia and infiltration, there is mucosal damage and inflammation and possibly similar factors are involved in the development of these changes in both conditions.

During this study L Roberts was in receipt of a Wellcome Trust Scholarship. The authors wish to thank Mr R James for the photography and Mr B Kelly and his staff for excellent technical assistance.

\section{References}

${ }^{1}$ Beister HE, Schwarte LE. Intestinal adenoma in swine. Am J Pathol 1931; 7: 175-85.

${ }^{2}$ Westendrop JF. Terminale Jejuno-ileitis Bij Het Varken. 1965, Utrecht: Thesis. 
${ }^{3}$ Dodd DC. Adenomatous intestinal hyperplasia (proliferative ileitis) of swine. Path Vet 1968; 5: 333-41.

${ }^{4}$ Rowland AC, Rowntree PGM. A haemorrhagic bowel syndrome associated with intestinal adenomatosis in the pig. Vet Rec 1972; 91 : 235-41.

${ }^{\mathbf{5}}$ Reference deleted.

${ }^{6}$ Rowland AC, Lawson GHK. Porcine intestinal adenomatosis: a possible relationship with necrotic enteritis, regional ileitis and proliferative haemorrhagic enteropathy. Vet Rec 1975; 97: 178-80.

${ }^{7}$ Rowland AC, Lawson GHK, Maxwell A. Intestinal adenomatosis in the pig: occurrence of a bacterium in affected cells. Nature 1973; 243 : 417.

${ }^{8}$ Lawson GHK, Rowland AC, Wooding P. The characterisation of Campylobacter sputorum subspecies mucosalis isolated from pigs. Res Vet Sci 1975; 18: 121-6.

${ }^{9}$ Roberts L, Rowland AC, Lawson GHK. Experimental reproduction of porcine intestinal adenomatosis and necrotic enteritis. Vet Rec 1977; 100: 12-3.

${ }^{10}$ Rowland AC, Lawson GHK. Intestinal adenomatosis in the pig: immunofluorescent and electron microscopic studies. Res Vet Sci 1974; 17: 323-30.

${ }^{11}$ Lawson GHK, Rowland AC. Intestinal adenomatosis in the pig: a bacteriological study. Res Vet Sci 1974; 17: 331-6.

${ }^{12}$ Young BJ. A reliable method for demonstrating spirochaetes in tissue sections. J Med Lab Technol 1969; 26: 248-52.

12a Vivotec J. Carcinomas of the intestine in cattle and pigs. Zentralbl Veterinaermed A 1977; 24: 413-21.
${ }^{13} \mathrm{Head} \mathrm{KW}$. Tumours of the lower alimentary tract. Bull WHO 1976; 53: 167-86.

${ }^{14}$ Rijke RPC, Hanson WR, Plaisier HM, Osborne JW. The effect of ischemic villus cell damage on crypt cell proliferation in the small intestine. Evidence for a feedback control mechanism. Gastroenterology 1976; $71:$ 786-92.

${ }^{15}$ Pascal RR, Kaye GI, Lane N. The colonic pericryptal fibroblast sheath: replication, migration and cytodifferentiation of a mesenchymal cell system in adult tissue. I. Autoradiographic studies of normal rabbit. colon. Gastroentereology 1968; 54: 835-51.

${ }^{16}$ Kaye GI, Lane N, Pascal RR. The colonic pericryptal fibroblast sheath: replication, migration and cytodifferentiation of a mesenchymal cell system in adult tissue. II. Fine structural aspects of normal rabbit and human colon. Gastroenterology 1968; 54: 852-65.

${ }^{17}$ Kaye GI, Pascal RR, Lane N. The colonic pericryptal fibroblast sheath: replication, migration and cytodifferentiation of a mesenchymal cell system in adult tissue. III. Replication and differentiation in human hyperplastic and adenomatous polyps. Gastroenterology $1971 ; 60: 515-36$.

${ }^{18}$ Dyson JL. Herniation of mucosal epithelium into the sub-mucosa in chronic ulcerative colitis. J Clin Pathol 1975; 28: 189-94.

${ }^{19}$ Scott GBD, Keymer IF. Mucosal herniations in the colons of non-human primates. $J$ Pathol 1976; 120: 177-81.

${ }^{20}$ Cook MG, Goligher JC. Carcinoma and epithelial dysplasia complicating ulcerative colitis. Gastroenter ology 1975; 68: 1127-36. 